\title{
O GRITO ELETRÔNICO: uma análise do site Overmundo
}

\section{Carlos Calenti}

Graduação em Comunicação Social - Jornalismo pela Universidade Federal do Espírito Santo (2007). Mestrado em Comunicação e Cultura na ECO/UFRJ (2010), pesquisando relações de poder e produção de subjetividade nas mídias colaborativas. Doutorando em Comunicação e Cultura pela UFRJ.

\section{Resumo}

Esse artigo procura fazer uma análise das relações de poder no site Overmundo, exemplo brasileiro de uma Rede P2P. Analisamos as discussões que levaram a sua configuração atual e a forma com que hoje a comunidade participa de suas atividades. Também buscamos refletir sobre o motivo que levou à desmobilização atual dos seus colaboradores e à estagnação do site.

\section{Palavras-chave}

Overmundo. Rede P2P.

\section{THE ELETRONIC SHOUT: an analysis of the site Overmundo.}

\begin{abstract}
The subject of this paper it is the website Overmundo, an important example of a brazilian P2P practice, and its politics. Our goal it is to analize the discussions that lead to its current configuration and the way that the community participates of its activities. We also want to reflect on the reason of the current demobilization of its colaborators and the webiste stagnation.
\end{abstract}

Keywords

Overmundo. P2P networking.

\section{INTRODUÇÃO}

Para introduzir esse artigo, sobre o site colaborativo brasileiro Overmundo, é necessário deixar claro que o grosso das análises e do processo de coleta de dados e intervenção no dia a dia da comunidade foi feito para a minha dissertação, "Relações de poder e produção de subjetividade nas mídias colaborativas: uma análise do site Overmundo", apresentada na Escola de Comunicação da UFRJ em março de 2010. Portanto, há três anos. Para qualquer site, três anos é muito tempo. Para uma página colaborativa, em que a comunidade tem grande peso nos processos decisórios e na organização do conteúdo, três anos deveria ser ainda mais determinante. É sintomático, então, que pouco tenha mudado nesse tempo - pelo menos se contarmos, como é o nosso caso, a estrutura de colaboração proporcionada pelo site, e não os seus meandros administrativos. De qualquer forma, para esse artigo procuramos atualizar as informações coletadas, e, para além das conclusões feitas 
com a dissertação, procuramos refletir também o que causou essa aparente estagnação do Overmundo, quando antes, uma de suas principais características era exatamente a sua constante transformação.

\section{APRESENTAÇÃO E CONSTITUIÇÃO}

Está lá, na seção Ajuda, que explica o fundamento do Overmundo para os usuários de primeira viagem e desavisados em geral:

O Overmundo é um website colaborativo dedicado à difusão da produção cultural brasileira e das comunidades de brasileiros no exterior, com foco em seus aspectos que não costumam receber cobertura da grande mídia. (OVERMUNDO, 2010).

Aí estão dadas as bases do site: a divulgação da cultura brasileira de forma descentralizada, das manifestações que comumente não encontram espaços nos grandes veículos de comunicação. E, para fazer esse trabalho, para falar da cultura espalhada por todo o Brasil, e não só no eixo Rio - São Paulo, quem melhor do que os próprios moradores, ou fazedores de cultura espalhados por todo o país? Por isso o Overmundo é um site colaborativo, em que todos podem postar notícias, obras, comentar, discutir, produzir e etc. sempre tendo como horizonte a nossa cultura. A partir dessa ideia central, o site se desdobra em algumas seções. As principais, voltadas especificamente para o trabalho de divulgação e discussão da cultura brasileira são: Overblog, onde se podem publicar matérias e entrevistas sobre a cultura brasileira; o Banco de Cultura, onde podem ser disponibilizados produtos feitos pelos participantes: músicas, vídeos, fotos, teses, poesias, contos e etc.; o Guia, onde os usuários podem publicar pontos interessantes de suas cidades (ou das que quiserem); e a Agenda, onde podem ser divulgados festas e eventos. Há também o Overmixter, uma espécie de outro site dentro do site, onde podem ser disponibilizados samplers, bases e vocais de músicas, ou as próprias músicas, para que elas possam ser remixadas (mas sobre o qual não trataremos nessa pesquisa). Outras seções servem mais como mecanismos compartilhados de funcionamento do site, como o Fórum de Ajuda e a edição colaborativa. Existem ainda os perfis de todos os usuários, que criam uma rede social em torno do Overmundo, e o Observatório, blog da equipe moderadora, que publica as últimas novidades, dentre outras coisas. Para a publicação de um conteúdo no site é necessário, primeiramente, o preenchimento de um cadastro, destinado à criação de um perfil que possa postar, votar e comentar. 
Após essa etapa, já devidamente logados, os usuários vão para a parte publicar, onde eles escolherão a seção à qual sua colaboração se destina, dentre as já citadas. Para se publicar no Overmundo é preciso estar em conformidade com o fato de que qualquer coisa no site está sob uma licença Creative Commons BY-NC-SA 3.0, que significa que o conteúdo pode ser distribuído livremente e que se podem criar obras derivadas a partir dele, desde que se dê crédito ao autor, que não se utilize a obra com finalidade comercial e que a obra derivada seja protegida pela mesma licença. Na hora de publicar, pode-se escolher entre publicar o conteúdo automaticamente ou mandá-lo para a edição colaborativa, onde ele ficará durante 48 horas, tempo em que todos os membros da comunidade que quiserem podem sugerir alterações na colaboração, no caso, por exemplo, de erros gramaticais, de formatação na página, ou mesmo de informação, e etc., e também indicar se a contribuição está fora de lugar (cabe à moderação do site verificar se o alerta dado pelos usuários é válido ou não). Depois desse tempo, as colaborações são publicadas e vão automaticamente para a seção de colaborações recentes, onde ficarão em destaque durante mais 48 horas, recebendo votos dos usuários. Atualmente todos os usuários têm o mesmo peso do voto, ou seja, o voto de cada colaborador vale 1 ponto. Quanto mais o tempo passa, no entanto, um algoritmo diminui a pontuação, calculando assim os chamados overpontos. As contribuições com mais overpontos têm mais destaque no site - seja na sua home page ou nas páginas específicas de cada seção. Assim, as três colaborações para o Overblog com mais overpontos vão para a home, assim como as quatro mais pontuadas do Guia e da Agenda. No caso do Banco de Cultura, a colaboração mais votada de cada subseção vai para a página principal (as subseções são: poesia, texto ficção, texto não ficção, artes visuais, cinema e vídeo e música). Esse sistema de votação garante que as coisas mais relevantes para a comunidade do Overmundo tenham mais visibilidade dentro do site.

A seguir discorreremos sobre o processo de formação do site e as mudanças constantes na sua história que o levaram à configuração que acabamos de descrever.

\section{O Overmundo e seu processo constituinte}

Como já falamos acima, o blog Observatório é uma seção do site que os moderadores utilizam para dialogar com a comunidade de colaboradores. Através dos seus posts, que remontam à 16 de março de 2006, eles publicam as mudanças pelas quais o Overmundo passa, as parcerias firmadas, os conteúdos que eles acreditam que valem ser ressaltados, dentre outras coisas. Nesse espaço também já ocorreram muitas discussões entre usuários e 
moderadores, tanto sobre mudanças já ocorridas quanto sobre os rumos que o site tomou e poderia tomar. Por ser um lugar dentro do Overmundo que une em si um registro tanto das suas transformações quanto das tensões e colaborações que ajudaram o site a chegar ao que é hoje, o escolhemos como a fonte principal para entender os caminhos de sua constituição.

$\mathrm{Na}$ arqueologia de seus posts, descobrimos, por exemplo, que antes da sua estreia aberta, no dia 7 de março de 2006, o Overmundo era um blog fechado para comentários. Isso durante três meses, em que a equipe construía o site tal qual ele veio a existir. Nessa época, quando foi ao ar já aberto às participações, o site era um tanto diferente quanto à publicação. Primeiramente todos os conteúdos tinham que, obrigatoriamente, passar por duas filas: a fila de edição, onde ele ficava durante 48 horas e cuja função é exatamente a mesma da edição colaborativa atual; e depois, automaticamente, para a fila de votação, onde ele ficava por mais 48 horas, recebendo os votos da comunidade. Só se a colaboração recebesse um determinado número de votos seria publicada (nesse começo eram 20, mas depois passou pra 40, 60 e por fim se tornou um algoritmo, transferindo uma decisão política antes de posse da moderação para uma ferramenta aparentemente "imparcial", ainda que a transformação seja reflexo exatamente das constantes reclamações sobre a alta do número de votos de corte) - se não recebesse, iria somente para a página pessoal da pessoa que a propôs. Mas, desde esse primeiro post, uma reclamação, que repercutiu ainda durante muito tempo, com muitos usuários compartilhando da mesma opinião, era feita: o material demorava muito tempo a ser postado, as filas eram muito lentas. Em resposta a esse tipo de comentário, Hermano Viana, um dos idealizadores e fundadores do site, declarou nos comentários do blog:

\footnotetext{
(...) eu sei que demora. Podemos mudar isso... Mas o objetivo é que mais gente possa opinar sobre as colaborações, antes delas serem publicadas. Um dia seria muito pouco, não seria? Todo mundo teria que entrar aqui todos os dias para não perder nada. (VIANNA, 2006).
}

Também através do Overblog, mais especificamente do post Karmas, perfis e outras novidades, descobrimos outra importante ferramenta, que foi determinante nas participações do site por muito tempo: o karma, sistema de reputação que influía diretamente na forma de publicação e no poder de cada usuário na definição do que era importante para a comunidade. A chegada do karma trouxe consigo uma diferenciação no peso dos votos de cada usuário - a partir desse momento, ele dependia do karma dos mesmos. E o karma era um número imputado a cada colaborador calculado em relação à participação desses no site: quanto mais ele tivesse participado, seja com votos, comentários, colaborações, votos de outros membros para as suas colaborações e etc., em menos tempo, e na maior diversidade de seções, maior 
seria o seu karma. Dessa forma, os overpontos garantiam (e garantem) que os temas de maior importância para a comunidade ganhassem maior destaque, e os karmas garantiam que as pessoas com maior engajamento na construção do Overmundo tivessem um peso maior na decisão do que era ou não relevante. O sistema que relacionava o número de pontos de karma com o peso do seu voto se dava assim: até 25 pontos, os votos tinha peso 1; 26 a 100, peso 2; 101 a 250, peso 3; 251 a 500, peso 4; 501 a 750, peso 5; 751 a 1000, peso 6; 1001 a 1500, peso 7; 1501 a 2500, peso 8; 2501 a 5000, peso 9; acima de 5000 pontos, peso 10. Assim, por exemplo, um colaborador com mais 5000 de karma, ao votar numa colaboração, lhe adicionava 10 overpontos. Nesse post em particular, quase todos os comentários elogiaram o sistema de karmas como uma forma de movimentar o site e estimular o envolvimento dos participantes.

No entanto, em posts futuro fica latente um receio de que os chamados "fominhas de karma", que comentam e postam e votam alucinadamente só para o aumento do karma, pudessem prejudicar a qualidade do que era publicado, pois no seu afã eles votariam em qualquer colaboração, e não naquelas que eles considerassem as melhores. Durante as discussões do Overblog, sejam aquelas postadas pelos moderadores ou as travadas no espaço dos comentários, o problema das panelinhas foi citado muitas vezes, como nesse comentário da colaboradora Apple:

Panelas por aqui? Têm demais... o quê mais têm é ente votando ou deixando de votar após saber quem é o autor da publicação. (APPLE, s/a)

E a questão de certo desvio causado pelo karma também aparece:

O fato de os de maior karma terem poder de decidir que trabalhos ganharão posição
de destaque é falho e acabou produzindo aberrações que comprometem a
credibilidade do Overmundo. Isso porque qualquer pessoa pode se cadastrar no site,
votar aleatoriamente e adquirir peso de decisão. (REZENDE, 2006)

Essas são discussões que se sucederam diversas vezes. O que ressalta a tensão existente tanto entre os usuários e o sistema criado pelos moderadores, quanto entre os próprios usuários, ou ainda entre grupos de usuários. E foram essas discussões que resultaram, eventualmente, no fim do sistema de karma e da prática de gamming, de utilização dessa ferramenta baseada na disputa por visibilidade e não na real preocupação com a eleição dos melhores conteúdos para a comunidade. Acreditamos que o sistema de karma foi uma solução bastante engenhosa de organização do poder na comunidade, criando hierarquias flexíveis (pensando nas Redes P2P), dando mais poder àqueles membros mais engajados no exercício 
diário do Overmundo, caminhando sempre para um poder mais descentralizado quanto fosse possível. No entanto, ao acompanharmos o desenvolvimento do site, fica claro que essa experiência não deu certo - a hierarquização dos usuários baseada na participação acabou por se confrontar com o desejo de qualidade das colaborações. O Overmundo acabou virando uma espécie de jogo. E apesar de acreditarmos que disputas por poder sempre existirão, e não é diferente no ambiente das mídias colaborativas, essa em particular se tornou danosa para a própria existência do site.

Outra discussão recorrente no Observatório que acabou demandando uma ação da moderação discorria sobre as colaborações fora do lugar. Seja por estar deslocada na seção em que se encontra (um poema no Overblog, por exemplo), ou por não se encaixar de forma nenhuma no perfil do site. Assim, a coordenação criou uma ferramenta de edição chamada “colaboração fora de lugar”, como é explicado no post Novas ferramentas para socializar decisões. Essa ferramenta era na verdade um botão, situado abaixo do título das colaborações a partir da Fila de Votação, que todos os membros logados da comunidade podiam apertar no caso dos problemas citados acima, ou ainda de spam. Após certo número de pessoas acionarem o botão, a colaboração era removida da seção a qual se destinava, e ficava visível apenas na página pessoal do colaborador (posteriormente, em outra mudança, a colaboração passou a ser removida completamente do site). O fato do número de votos necessários para um conteúdo ser removido não ser divulgado, feria, acreditamos, um dos conceitos das redes P2P: o holoptismo, em que as informações relevantes ao funcionamento do site deveriam ser socializadas também. E essa questão foi de fato um problema levantado. Essa opacidade era justificada como forma de evitar que o recurso virasse um jogo entre grupos de colaboradores que quisessem prejudicar uns aos outros. Com o tempo (mais precisamente depois de oito meses), no entanto, pelos problemas levantados na comunidade (acusações de censura e perseguição), o botão foi alterado e se transformou em alerta (como é hoje), que, ao ser apertado, leva a uma página com várias possibilidades de desvios do conteúdo - fora da proposta editorial do site ou publicado na seção errada, conteúdo ofensivo ou discriminatório e publicidade / spam - a serem escolhidos (como é explicado no post Novidades nos trilhos). Essa reclamação é repassada para a moderação, que a partir daí tem o poder de decidir se o conteúdo deve ou não ser retirado do Overmundo.

Todas essas transformações evidenciam algumas características importantes do que foi o Overmundo e que podem nos ajudar a entender como ele se encontra hoje e o porquê disso. Primeiramente, elas denotam o quanto o Overmundo foi um site movimentado. Ainda que o gamming dos karmas tenha sido danoso para o seu desenvolvimento naquele período, ele 
também queria dizer que as pessoas se importavam com o site, com a visibilidade que ele proporcionava, com seu lugar naquela rede. De fato, todas essas discussões denotam uma grande preocupação da comunidade com os rumos do site. E o mais importante: a comunidade, através da manifestação contínua nos espaços do Overmundo, sempre teve a capacidade de transformar suas configurações. No entanto, como reverso da medalha, ao mesmo tempo em que a comunidade se engajou na constante melhoria e transformação da rede, essas transformações acabaram por ter um caráter desmobilizador: o fim da disputa por karma, a transferência de certas atribuições para algoritmos, a crescente centralização de poder nas mãos da moderação (como no caso do botão Alerta), e ainda outras, como o fim dos Fóruns, que eram espaços onde a própria comunidade podia pautar discussões sobre o rumo dos sites de forma espontânea, o que depois acabou confinado apenas nos comentários do Overblog. De qualquer forma, elas mostram o quanto a comunidade foi viva e determinou os caminhos que o Overmundo percorreu.

\section{RELAÇÕES DE PODER}

Partindo, agora, para a análise do site como ele se apresentava em 2010, quando da coleta de dados a seguir, e que, em análise recente, pudemos constatar que pouco mudou. Para começar, será falada da relação entre o site e as forças do mundo exterior que o atravessam incessantemente. Com isso se quer dizer que, apesar do foco na pesquisa ter sido as relações internas de poder no site, não se pode deixar de ressaltar as relações do site com o seu fora.

E uma dessas relações está clara desde o início: a posição do Overmundo em relação às mídias de massa. $\mathrm{O}$ site surgiu exatamente desta tensão, da falta de atenção que a imprensa brasileira dava (e dá) às movimentações culturais que não estão centradas entre Rio de Janeiro e São Paulo. O Overmundo é claramente uma resposta a essa falta de cobertura, tentando divulgar a cultura do Brasil de forma mais abrangente e democrática. A escolha da internet como meio não é por acaso, e muito menos a utilização das ferramentas colaborativas. Pois foi através da internet e das mídias colaborativas, como facilitadoras da sua utilização para a produção e veiculação de conteúdos feitos por potencialmente qualquer um, que a luta pela democratização da comunicação ganhou novo ânimo. A web se tornou uma plataforma política, de luta dos trabalhadores imateriais por uma produção (e uma organização da produção) mais livre nos tempos em que sua vida é toda produtiva, e também muitas vezes apropriada nas redes do capitalismo cognitivo. O Overmundo foi buscar nas mídias colaborativas a possibilidade de fazer vozes de todo o Brasil se expressarem sobre a sua 
própria cultura. Pois essa era mesmo a forma mais propícia para se abarcar tantas manifestações espalhadas por um território tão imenso, não mandando alguns poucos repórteres cobrirem algumas poucas coisas, mas organizando um jeito das pessoas desses lugares poderem relatar suas vivências, e as reunindo num só lugar para dar visibilidade a esses relatos. E, ainda, dando-lhes poderes de decidir que assuntos e abordagens lhe são mais interessantes. Assim, o Overmundo se tornou uma rede produtiva, uma dessas em que o trabalhador imaterial produz sua própria subjetividade. O Overmundo se colocou dentro da própria luta da multidão.

E, nesse sentido, é muito coerente a relação do site com o Creative Commons. Todo e qualquer conteúdo publicado no Overmundo está automaticamente sob uma licença Creative Commons de propriedade intelectual. Essas licenças são ferramentas internacionais que reservam alguns direitos ao autor do conteúdo licenciado, ao mesmo tempo em que, num contraponto direto com as leis de copyright, também protegem o que são considerados como direitos da sociedade. Assim, em vez de "todos os direitos reservados", temos o slogan "alguns direitos reservados". O Creative Commons possui diversas licenças diferentes, com maior ou menor grau de abertura dos conteúdos à circulação sem o controle do produtor. A licença específica utilizada pelo Overmundo é a 3.0 Brasil. Sob as suas condições, todos os conteúdos podem ser copiados, distribuídos, exibidos ou executados e ainda há a possibilidade de se criar obras derivadas a partir dele. A ideia do Creative Commons e que é compartilhada pelo Overmundo, portanto, é a ideia de uma Cultura Livre (termo cunhado por Lawrence Lessig). Se pensarmos na incrível proliferação das redes de difusão e produção da informação que a internet possibilitou, na descentralização e distribuição dos papéis de produtores e consumidores, e em como isso é possibilitado pela livre troca de informações e pela livre comunicação, então a ideia do copyright como existe hoje é cerceadora dessa troca, que caracteriza, por exemplo, o próprio diálogo que o Overmundo cria. As leis de copyright são cerceadoras do próprio tecido produtivo que caracteriza o trabalho imaterial.

Esses projetos acreditam, então, numa ideia de cultura (e de informação) que possa circular livremente, sem constrangimentos, para que nesse processo de constante diálogo e propagação possa se enriquecer. E ainda assim garantindo ao autor um controle bastante largo sobre a sua obra, ao mesmo tempo em que possibilita ao resto da sociedade o livre usufruto dos seus trabalhos. Assim, ao utilizar tal licença o Overmundo se posiciona politicamente mais uma vez ao lado da luta da multidão. Nesse mesmo sentido, o Overmundo tem o seu código-fonte do site aberto, sob a licença CC-GNU GPL, livre para se aperfeiçoado pela 
comunidade, ou para ser usado por outras experiências colaborativas que queriam se beneficiar da estrutura básica do site, apoiando, assim, a importante luta do movimento do software Livre. Como visto acima, o Overmundo se põe ativamente na luta pela democratização da comunicação e pela livre circulação (e produção) de informação. Será falado, a partir de agora de suas relações de poder internas.

\section{CONSIDERAÇÕES FINAIS}

Voltar, como pesquisador, ao Overmundo em 2013, não posso deixar de expressar, foi sim decepcionante. $\mathrm{O}$ escolhi como objeto de pesquisa ainda antes do mestrado, quando fiz minha monografia de conclusão do curso de jornalismo, em 2007. E essa escolha se deu pela importância do site na web brasileira, que, inclusive, tinha, e ainda tem, um dos maiores PageRanks do país. De fato, o espaço que sempre ocupou, de divulgador de expressões culturais brasileiras com pouca visibilidade, continua sendo fundamental e pouco explorado. A aposta na colaboração para exercer esse papel - como explicitamos - também nos parece ao mesmo tempo óbvia e inovadora. Mas por que, então, um site que já foi tão vivo, hoje nos parece tão estático?

Bauwens (2006), ao falar das Redes P2P, conceituação sob a qual podemos localizar as mídias colaborativas e o Overmundo, diz que elas são caracterizadas por serem redes distribuídas, baseadas na livre cooperação, em que qualquer pessoa pode participar em que há uma horizontalidade no acesso às informações relativas à rede, em que a hierarquia é flexível e baseada nos méritos dos usuários e que produz um tecido comum de produção, um commons. E, certamente, muitas dessas características ainda se aplicam ao site: qualquer um pode colaborar e, de certa forma, participar da organização do site pelos votos. Mas, se olharmos mais atentamente, também é patente o quanto o Overmundo se afastou, mesmo que poucos passos, desses principios. O karma garantia uma hierarquia flexível que fazia com que os mais engajados na comunidade tivessem mais poder decisório (e que muitos buscassem esse espaço e se engajassem mais), mas ele não existe mais. Assim como os Fóruns, que garantiam que todos pudessem pautar suas discussões em relação aos rumos do Overmundo. E nem todas as informações estão de posse da comunidade, como as decisões acerca das colaborações fora de lugar. Se no começo o Overmundo parecia alienar aqueles usuários que não estavam dispostos a ter um engajamento maior no site para poder postar seus conteúdos, aos poucos o jogo se inverteu e ele passou a afastar exatamente aqueles mais preocupados em 
se envolver com as suas decisões e o seu dia a dia. Alia-se a isso o fato de que a seção mais movimentada do site hoje seja o Banco de Cultura, que nunca foi vista pela moderação como a mais importante, e, a nosso ver, temos os fatores decisivos para que o Overmundo hoje não seja mais palco de grandes engajamentos da comunidade, de discussões nos comentários, de disputas acirradas, de transformações contínuas.

No dia 13 de dezembro de 2012, o Observatório publicou um post relatando uma mudança no comando do site, que diz:

\begin{abstract}
Não pode ser maior a alegria, portanto, nem mais profundo o sentido, de anunciar a nova parceria, com o cavaleiro do Overmundo passando agora a ser abrigado pela rede de coletivos do FdE. A partir de hoje o site entra em nova etapa, com a turma do Fora do Eixo assumindo sua condução e animação, renovando o impulso da trajetória comum e a vocação do Overmundo para a promoção de novos 'links' de criações e criadores de cultura de todo o Brasil. (OBSERVATÓRIO, 2012)
\end{abstract}

No entanto, até o momento, março de 2013, não foram notadas muitas mudanças na gestão do site.

O Fora do Eixo parece, por enquanto, mais interessado em usar o site como difusor de conteúdo do que como rede de construção coletiva. Ficamos na expectativa, então, de que isso possa mudar e que todas as potencialidades criativas e políticas dessa plataforma possam se reanimar e voltar a ocupar seu espaço merecido nas discussões da cultura e da mídia alternativa brasileira.

\title{
REFERÊNCIAS
}

ANTOUN, Henrique. De uma tela à outra: a explosão do comum e o surgimento da vigilância participativa. In: ANTOUN, Henrique. Web 2.0: participação e vigilância na era da comunicação distribuída. Rio de Janeiro: Mauad X, 2008.

BARROS, Laura Pozzana de; KASTRUP, Virgínia. Cartografar é acompanhar processos. In: PASSOS, Eduardo; KASTRUP, Virgínia; ESCÓSSIA, Liliana de (Org.). Pistas do método cartográfico: Pesquisa-intervenção e produção de subjetividade. Porto Alegre: Sulina, 2009. p. 52-75.

BAUWENS, Michel. The political economy of peer production. 2006. Disponível em: <http://www.paecon.net/PAEReview/issue37/Bauwens37.htm>. Acesso em: 07 mar. 2013.

OBSERVATÓRIO (Brasil). Nova jornada para o Overmundo. 2012. Elaborado pela Equipe Overmundo. Disponível em: <http://www.overmundo.com.br/blogs/nova-jornadapara-o-overmundo-2>. Acesso em: 19 ago. 2014.

RECUERO, Raquel. Práticas de sociabilidade em sites de redes sociais: interações e capital 
social nos comentários do Fotolog.com. In: ANTOUN, Henrique. Web 2.0: participação e vigilância na era da comunicação distribuída. Rio de Janeiro: Mauad X, 2008.

REZENDE, Antônio. . 2006. Comentário ao post Overpontos e edição em 30 dez. 2006. Disponível em: <http://www.overmundo.com.br/blogs/overpontos-e-edicao>. Acesso em: 19 ago. 2014.

VIANNA, Hermano. . 2006. Comentário ao post Para início de conversa em 30 dez. 2006. Disponível em: <http://www.overmundo.com.br/blogs/para-inicio-de-conversa>. Acesso em: 19 ago. 2014. 